\title{
Monitoring the traceability, safety and authenticity of imported palm oils in Europe
}

\author{
Kirstie A. Goggin and Denis J. Murphy* \\ School of Applied Sciences, University of South Wales, Pontypridd, United Kingdom
}

Received 20 August 2018 - Accepted 3 October 2018

\begin{abstract}
This article describes the challenges of regulating and monitoring traceability and certification systems, and of ensuring the safety and authenticity of foodstuffs imported into Europe, particularly focusing on palm oils. Several measures have been implemented within palm oil supply chains to ensure that traceability can be monitored. However, these supply chains can be highly complex and, more often than not, full traceability is not achievable for stakeholders who only have access to existing systems. In Europe, measures for authenticity of palm oils are not presently as robust as those for other vegetable oils, which means that sometimes unsafe and inauthentic palm oils, often already incorporated into other products, can make their way onto supermarket shelves for unsuspecting consumers. Such instances are usually rare and are normally detected before products are purchased by consumers. Nevertheless, it is still the case that the addition of illegal and potentially harmful additives to palm oils destined for export to Europe is a regular occurrence, alerts for which can be found on the Rapid Alert System for Food and Feed (RASFF) portal. As the European Union has committed to only accept authenticated "sustainably sourced" palm oils, it is even more important to ensure that such imported oils are really from the declared source, preferably via proven analytical methods. This makes it more important that accurate and robust techniques are developed and implemented for verifying the provenance and authenticity of palm oils and their downstream products. Here, we review the underlying regulatory framework relating to traceability and authentication and assess some new and emerging chemically-based technologies that should contribute to improving the monitoring of palm oil and other vegetable oil supply chains in Europe and elsewhere.
\end{abstract}

Keywords: palm oils / traceability / authenticity / food safety / Europe

Résumé - Contrôler la traçabilité, la sécurité et l'authenticité des huiles de palme importées en Europe. Cet article décrit les défis de la réglementation et des contrôles des systèmes de traçabilité et de certification, ainsi que de la sécurité et de l'authenticité des denrées alimentaires importées en Europe, en particulier des huiles de palme. Plusieurs mesures ont été mises en œuvre au sein des chaînes d'approvisionnement en huile de palme pour assurer le suivi de la traçabilité. Cependant, ces chaines d'approvisionnement peuvent être extrêmement complexes et, le plus souvent, une traçabilité complète n'est pas réalisable pour les parties prenantes qui ont uniquement accès aux systèmes existants. En Europe, les mesures d'authenticité des huiles de palme ne sont pas aussi robustes que celles des autres huiles végétales, ce qui signifie que des huiles de palme parfois peu sûres et non authentiques, souvent déjà incorporées dans d'autres produits, peuvent être acheminées vers les rayons des supermarchés à destination de consommateurs non avertis. Ces cas sont généralement rares et sont normalement détectés avant que les produits ne soient achetés par les consommateurs. Pour autant, il n'en demeure pas moins que l'ajout d'additifs illégaux et potentiellement nocifs aux huiles de palme destinées à être exportées vers l'Europe est un phénomène courant dans les chaînes d'approvisionnement mondiales, des alertes pouvant être consultées sur le portail RASFF. Étant donné que l'Union européenne s'est engagée à n'accepter que des huiles de palme authentifiées provenant de sources durables, il s'avère encore plus important de veiller à ce que ces huiles importées proviennent réellement de la source déclarée, de préférence via des méthodes analytiques éprouvées. Cela rend d'autant plus primordial que des techniques précises et robustes soient développées et mises en œuvre pour vérifier la provenance et l'authenticité des huiles de palme et des produits qui en

*Correspondence: denis.murphy@southwales.ac.uk 
découlent. Nous examinons ici le cadre réglementaire sous-jacent relatif à la traçabilité et à l'authentification et évaluons certaines technologies nouvelles et émergentes reposant sur la chimie qui devraient contribuer à améliorer la surveillance de la chaîne d'approvisionnement de l'huile de palme et d'autres huiles végétales en Europe et ailleurs.

Mots clés : huiles de palme / traçabilité / authenticité / sécurité alimentaire / Europe

\section{Introduction}

Over the past few decades, consumer trust and confidence in the official regulatory bodies that establish and monitor food safety and reliability standards has been weakened. This follows a series of historical and more recent disease outbreaks, food contamination incidents, animal welfare violations, sustainability violations, concerns over factors such as antibiotic use in livestock and even the use of some genetically modified organisms in food crops. In many cases, the gravity of such incidents has been inappropriately magnified by the media, leading to heightened consumer concern and increased pressures on regulatory agencies and politicians to take prompt and decisive action. The situation has been exacerbated by the sometimes contradictory conclusions of scientific reports and conflicting evidence from both national and international agencies regarding food safety that is then reported, sometimes inaccurately, by media outlets. As a result, it is hardly surprising that consumer consciousness of these issues has greatly increased and has resulted in elevated demands for improved methodologies and more rigorous standards for robust and transparent traceability, sustainability and authenticity systems within food supply chains.

In the European Council Regulation, EC 510/2006 (2006), three quality schemes, all related to the European Union (EU) agricultural product quality policy, have been introduced to increase consumer interest in product origin and quality. The European Commission has stated that: "a constantly increasing number of consumers attach greater importance to the quality of foodstuffs in their diet than to quantity". The three introduced schemes: Protected Designation Of Origin (PDO), Protected Geographical Indication (PGI) and Traditional Speciality Guaranteed (TSG) were designed to ensure the quality and origin of foodstuffs produced in Europe. These are very important initiatives, but they leave open the question of "how we can most effectively monitor and assure the quality of foodstuffs produced elsewhere and imported into Europe?".

\section{Europe and palm oil}

The African oil palm, Elaeis guineensis, is an exceptionally high yielding tropical perennial crop which produces the two types of internationally traded palm oil, namely palm oil and palm kernel oil. These two oils are produced because $E$. guineensis palms bear prolific quantities of fresh fruit bunches, each containing between 1000-3000 individual fruits. High quality oil can then be extracted either from the fleshy mesocarp or from the seed-bearing kernels of these fruits. Palm oil, extracted from the fleshy fruit mesocarp, is a deep orangered oil, whilst palm kernel oil is a white-yellow oil that is extracted mainly from the endosperm tissue in the kernel (seed) of the fruit. These two oils have very different fatty acid
(FA) compositions which means they are utilised for a range of different downstream applications by different industries. In general, palm oil is most commonly utilised for edible applications as a solid vegetable fat (melting point about $35^{\circ} \mathrm{C}$ ). In contrast, palm kernel oil is a less dense product (melting point about $24^{\circ} \mathrm{C}$ ) that is mostly used for non-edible applications, especially as a major ingredient in many detergents and cosmetics.

During the past 50 years, oil palm has become established as the most important and productive global oil crop, producing about $35 \%$ of all traded vegetable oil on less than $10 \%$ of the land allocated to oil crops (Meijaard et al., 2018). Due to its perennial nature, oil palm trees can be harvested continuously year-round meaning that the crop can support livelihoods for large numbers of plantation workers and smallholder farmers (Murphy, 2015). This contrasts with the more highly mechanised, and completely seasonal production cycle of lower yielding temperate oil crops such as olives, soybeans, sunflowers or rapeseed (Murphy, 2014).

\subsection{European consumption and imports}

As oil palm crops can only be grown in tropical climates, Europe cannot produce its own palm oils and relies entirely on imports-whether destined for use in foods, cosmetics, biofuels or oleochemicals. Europe is, after India, the second largest global importer of palm oils, most of which come from Indonesia and Malaysia (Murphy, 2014). In 2016, almost 24 million tonnes of vegetable oils were consumed in Europe (Statista, 2015), approximately $32 \%$ of which were palm oils, as shown in Figure 1 (Indexmundi, 2017). Although the majority of imported palm oils in Europe is used in the food industry, the increased use of esterified palm oil in biodiesel has resulted in an annual increase in rate of European consumption of around $7 \%$, since 2010. In contrast, the consumption of edible palm oil has decreased slightly in recent years. This decline mirrors an overall decline in the use of solid fats, especially in processed food products, due to heath concerns about fat intake in general, particularly saturated fat consumption. In the case of palm oil, the decline might also reflect sustainability concerns about aspects of the environmental context of oil palm cultivation (see Sect. 3 below) that have impacted on both consumers and food manufacturers in Europe (CBI Ministry of Foreign Affairs, 2016a). Hence, European imports of palm oil decreased at an annual rate of $2.4 \%$ between 2011 and 2015 .

Although all palms oils imported into Europe originate from developing countries in tropical regions, about $34 \%$ of the oils first enter Europe through transit countries like the Netherlands where the vast majority of the entrepôt trade is delivered via the port of Rotterdam, where major oil palm producers such as Cargill, Sime Darby, Wilmar and IOI Loders have refineries. In general, Indonesian and Malaysian exports 


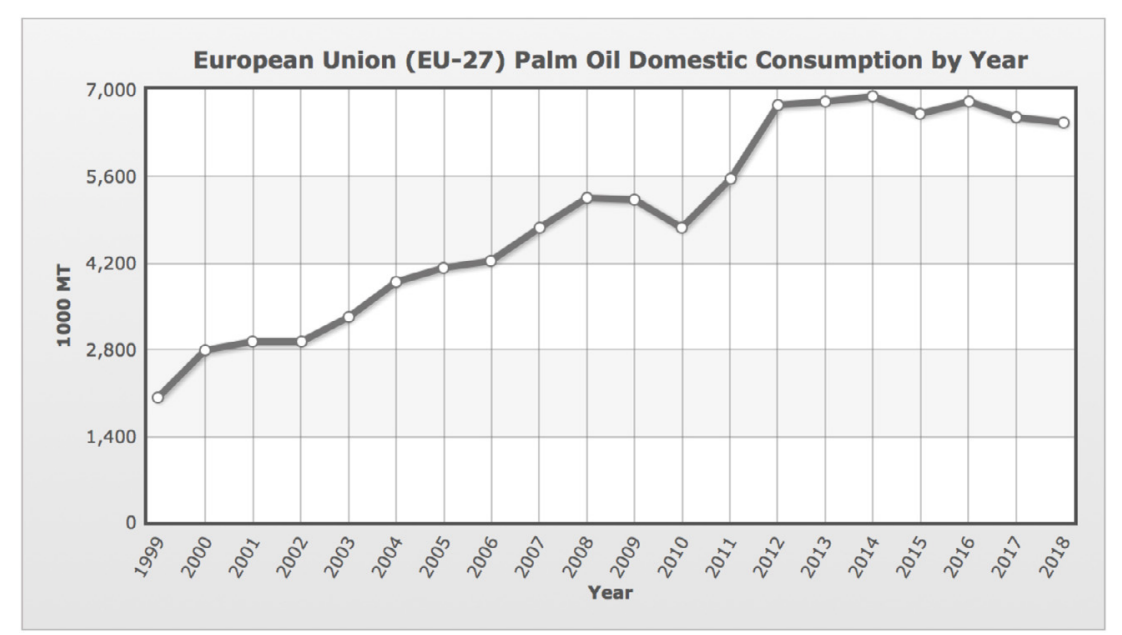

Fig. 1. European consumption of edible palm oil by year, in million tonnes (source: https://www.indexmundi.com/agriculture/?country= eu\&commodity=palm-oil\&graph=domestic-consumption).

Rank Country
$1 \underline{\text { India }}$
$2 \underline{\text { EU-27 }}$
$3 \underline{\text { China }}$
$4 \underline{\text { Pakistan }}$
5 Bangladesh
6 United States
$7 \underline{\text { Egypt }}$
8 Philippines
9 Russian Federation
10 Viet Nam
11 Myanmar
12 Japan
13 Kenya
14 Malaysia
15 Turkey

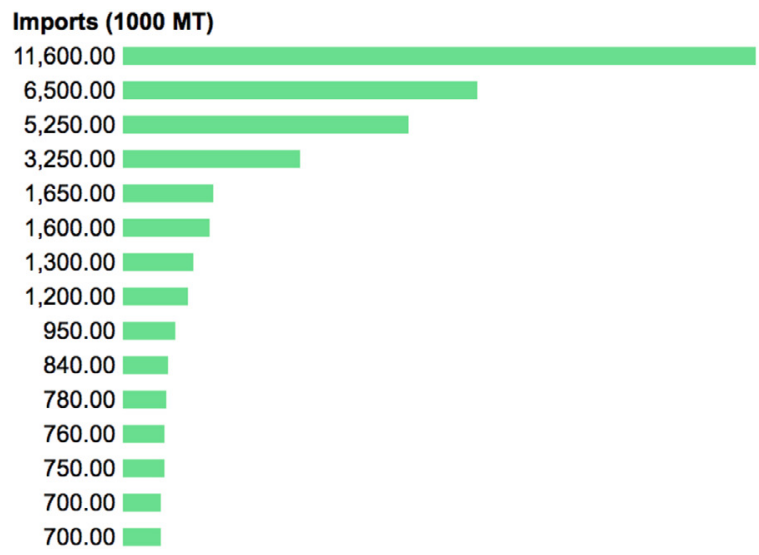

Fig. 2. Top 15 Importers of palm oils globally, in million tonnes (source: https://www.indexmundi.com/agriculture/?commodity=palmoil\&graph=imports).

of palm oil have decreased in recent years, whilst exports from other developing countries such as Colombia and Guatemala have begun to increase (CBI Ministry of Foreign Affairs, 2016 a) - this is perhaps associated with sustainability concerns from consumers and manufacturers, but also potentially due to higher imports within Asia. Another emerging, albeit still relatively small, palm oil exporting region is West Africa where palm cultivation is rising rapidly, largely for local consumption, but also due to a small but growing demand for unprocessed red palm oil, which is produced and shipped to specialised health-food retailers in Europe (see below for a discussion of some recent episodes of adulteration involving red palm oil).

There is little doubt that the relationship between Europe and the palm oil industry in general, and particularly many of the Malaysian and Indonesian producers, is somewhat strained at present. Although Europe remains the second largest importer of palm oils globally, as shown in Figure 2 (Indexmundi, 2018), the EU parliament has recently an- nounced restrictions on palm oil imports destined for use in biofuels and is moving towards an outright ban on such imports in the 2020s. The EU has also committed to using only palm oil that is sourced from certified sustainable sources, such as RSPO certified sources, by 2020. The European Parliament resolution of 4th April 2017 on palm oil and deforestation of rainforests cited many reasons for the decision. According to this report, the consumption of palm oil and its derived processed goods was controversially alleged to play a major role in global deforestation (European Parliament, 2017). This is interesting in view of the fact that in the early 2000s, the EU had initially encouraged the import of vegetable oils, including palm oils, as part of a policy to increase the use of carbonneutral biofuels as replacements for non-renewable fossil fuels.

Ironically, it was this EU policy that was one of the factors that led to an increased demand for palm oil and a resulting increased conversion of tropical land, including rainforests, to oil palm cultivation (Murphy, 2014). Following the more 
recent volte face by the EU after concerns about the environmental impact of the EU biodiesel-fuelled conversion of land to oil palm plantations (European Parliament, 2017), it is now evident that in the near-term future Europe will greatly reduce its demand for palm-derived biodiesel. Moreover, the EU will also increasingly insist on importing only "certified sustainable" palm oils for all other applications including in foods. Imports of edible palm oil greatly exceed those of palm oil destined for biodiesel use, which means that this "certified sustainable" requirement will present for the EU a far more serious challenge than the one posed by implementation of the recent biodiesel regulations. This raises the question that if the EU is serious about their stated policy of sourcing $100 \%$ "sustainable" palm oil by 2020 , how will this policy be implemented within the highly complex international palm oil supply chains, and how will the "sustainability" of products be assessed and monitored?

\subsection{Legal requirements for palm oil entering European markets}

For anybody wishing to sell palm oil in European markets, there are several requirements to which they must adhere in order to trade legally:

- traceability-exporters should know and document all involved suppliers, know which products are used during production processes and label final products for traceability in case of any food safety or authenticity issues;

- hygiene and control-exporters should implement food management principles and subject food products to official controls, which will allow them to define critical control points;

- contamination - products destined for export must adhere to European legislation, which has set maximum levels for different contaminants (polycyclic aromatic hydrocarbons, aflatoxins, microbes, dioxins and polychlorinated biphenyls, heavy metals, pesticides, 3-MCPD and foreign matter);

- extraction solvents-only solvents approved by the EU can be used for production and refining of vegetable oils. There are however, maximum residue limits for such solvents, including hexane $(1 \mathrm{mg} / \mathrm{kg})$ and ethylmethylketone $(5 \mathrm{mg} / \mathrm{kg})$;

- product composition-products should be authentic and not contain any unauthorised additives. Exporters should adhere to European legislation for additives, enzymes and flavourings;

- labelling-legislation applies to pre-packed consumer products. Product labels must contain information regarding composition, manufacturer, storage methods and preparation. It is compulsory to include the specific vegetable origin of oils and fats. Allergens must also be explicitly labelled and highlighted in the list of ingredients;

- food contact materials - product packaging materials must comply with European legislation. It must not pose a risk to human health, change the composition of the food or alter its taste or odour. Exporters should not use restricted materials (CBI Ministry of Foreign Affairs, 2016b).

\subsection{Additional requirements for palm oil entering European markets}

Potential buyers may also need to abide by additional requirements to demonstrate their commitment to food safety, responsibility and sustainability:

- food safety certification-potential buyers will often request evidence of a food safety management system. Exporters can apply for certification from a recognised and trustworthy source to prove the quality and safety of their product;

- corporate responsibility-buyers often have their own code(s) of conduct, with regards to corporate responsibility. These code(s) of conduct address many issues such as environmental, social and economic impact. Potential buyers will sometimes conduct their own audits of a company;

- sustainable sourcing certification - sustainable sourcing of commodities like palm oil is becoming of great interest to potential buyers. Consumer consciousness and awareness has prompted the development of sustainable initiatives, which seeks to promote and increase sustainable production and trade;

- organic certification-due to increasing consumer-led demand, buyers in some markets might request organic certification. Should an exporter wish to market their product as organic, they must adhere to the European Regulation for organic production and labelling. Only then can the product carry the official EU organic logo;

- Rainforest Alliance-the Rainforest Alliance Sustainable Agriculture Network is a prominent sustainability scheme which focuses on environmental issues. They have recently developed their own sustainable palm oil certification scheme which is appearing on an increasing number of food products ranging from beverages to ice cream (CBI Ministry of Foreign Affairs, 2016b).

\section{Sustainability and palm oil}

As widely reported in the media in Europe, some parts of the palm oil industry have been linked to various adverse environmental and socioeconomic outcomes including, among others, habitat destruction, loss of biodiversity, increased greenhouse gas emissions and human and land rights violations. The potentially serious impacts of such concerns for the wider palm oil industry is demonstrated by continued proposals to increase tax on palm oils from politicians in the previous French Governments. Such taxes were proposed every year from 2012 until 2016. The initial proposed rate of $€ 300$ per tonne was gradually reduced down to $€ 90$ per tonne, however, this proposal was eventually defeated in July 2016 following strong campaigning from producing countries (Michail, 2016). The proposed tax was dubbed the "Nutella" tax by French media due to the "L'affaire Nutella" that occurred in France in 2015 (Murphy, 2015), when during a TV interview, the French ecology minister, Ségolène Royal, criticised the popular edible spread Nutella, for containing what she described as environmentally damaging palm oil and she then advised consumers to boycott the product. Luckily, there was a rapid response from the 


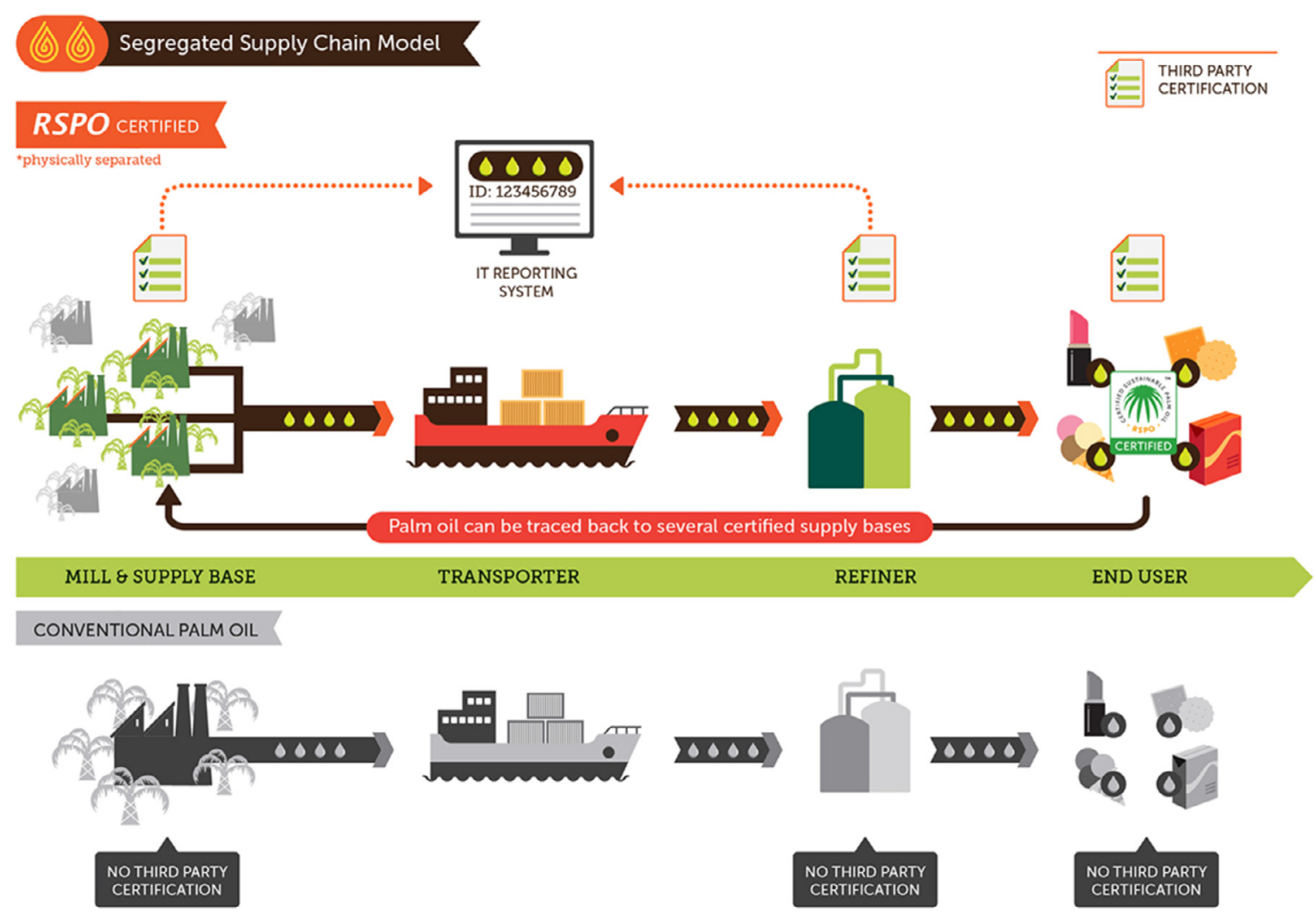

Fig. 3. An example of the RSPO segregated palm oil supply chain model (one of four RSPO supply chain models) compared to a conventional palm oil supply chain (source: https://rspo.org/certification/supply-chains).

industry where it was stated that Ferrero, the owner of the Nutella brand, sourced its palm oil from certified members of the Roundtable on Sustainable Palm Oil (RSPO). This led to an apology from the Minister who tweeted: "Mille excuses pour la polémique sur le Nutella" (Libération, 2015). Following the rejection of the proposed tax, French lawmakers then announced a reform of taxes on all vegetable oils and the introduction of a Sustainability Criteria Commission, which will define criteria for the production of vegetable oils.

These examples illustrate the sensitivity of public opinion to sustainability issues around palm oils and emphasises the need for credible supply chain management. This also means that the broader concept of sustainability is becoming an ever more important requirement for many exporters to address if they want to enter European markets. In response to demand from buyers, therefore, the industry is experiencing great pressure to move towards more transparent and verifiably sustainable methods of both production and sourcing of palm oils and their downstream products. Unfortunately, however, there is no single definition for sustainability with regard to the cultivation and processing of palm oil. A commonly used definition of sustainable practices is: "developments which meet the need of the present, without compromising the ability for future generations to meet their own needs". However, when we speak about sustainable palm oil production, what exactly is meant? Does it only relate to production that does not destroy primary rainforests? Or does it mean production that contributes to the conservation of species and/or wider biodiversity? Alternatively, does it also mean production that does not exploit children for labour?

Another factor to consider is that such rigorous standards have rarely, if ever, applied to other cropping systems that have historically had major impacts both on the environment and on biodiversity, so why focus so much on oil palm? Traditionally, sustainability has been related to maintaining or increasing yields within a given area. By this more limited definition, palm oil production is already highly sustainable because it is by far the highest yielding oil crop worldwide and hence has a much lower area footprint than any of the temperate oil crops. However, it is now widely acknowledged that the definition of sustainability should also take account of broader environmental and socioeconomic factors such as land rights, deforestation, greenhouse gas emissions, etc. Even with these additional factors, many conservationists argue that it is impossible to say any intensive farming system could be regarded as sustainable if the removal of natural habitats was, at some point, necessary for such a development (Meijaard et al., 2018). Ironically, therefore, if these criteria were applied to all of the cropping systems around the world, they would result in the definition of the vast majority of arable farming as being unsustainable.

In terms of the modern sustainability agenda as it is increasingly being applied to the palm oil supply chains, two main types of palm oil can be defined: "conventional" palm oil and "certified-sustainable" palm oil (Fig. 3). The "conventional" palm oil supply chain is one whose members are not part of a voluntary certification scheme such as the 
Roundtable on Sustainable Palm Oil (RSPO). These "conventional" oils need only adhere to sustainability legislations and regulations implemented by the governments in their region of origin. However, a recent study by Lyons-White and Knight (2018) discovered that some industry members found that national governments were not always decisive in the implementation of sustainability criteria, particularly nodeforestation commitments, thereby shifting the responsibility of enforcement back onto companies. This lack of consistent and effective regulation acted as a considerable barrier to improving sustainability, as individual companies lack the regulatory powers required to enforce the law (Lyons-White and Knight, 2018).

In contrast, a "certified-sustainable" supply chain is one whose members have voluntarily signed up to a certification scheme, usually managed by a Non-Government Organisation (NGO) like RSPO. In such cases, in order to become certifiedsustainable members of the scheme, companies must adhere to strict principles and criteria set by the NGO following consultations with some stakeholders in the oil palm industry. The principles and criteria are implemented to ensure that production has minimal impact on the environment and its associated communities. Demonstrating commitment to improving sustainability within the industry, Indonesian and Malaysian governments have developed their own certification schemes, Indonesian Sustainable Palm Oil (ISPO) and Malaysian Sustainable Palm Oil (MSPO), the former of which is already mandatory and the latter soon to become mandatory within these two major oil palm producing countries. There is much debate about how successful such schemes are and there have been concerns about their slow rate of uptake by palm oil users (Murphy, 2014). Nevertheless, the general consensus is that although they are not yet a "cure", these schemes are most certainly a step in the right direction in moving the industry towards the implementation of transparent and enforceable sustainability criteria.

\section{Traceability and palm oil}

The General Food Law Regulation (2002) defines traceability as "the ability to trace and follow food, feed and ingredients through all stages of production, processing and distribution". Traceability is a vital aspect of supply chain management for several reasons, but perhaps the most important is that it facilitates easy and rapid identification and isolation of a problem within a given supply chain, thus allowing the speedy withdrawal of a faulty or unsafe product from market. With regard to palm oil, the most important aspect of traceability is that it provides consumers with specific and accurate information about product origin, whilst ensuring that businesses can identify at least the immediate supplier of the product. It is important to note that in most cases, traceability models only allow for "one step back and one step forward" in a particular supply chain. This is unless other provisions are in place for increased traceability, such as an Identity Preserved (IP) supply chain, which is a lot more complex and expensive to implement, unless a single company either owns or effectively controls the entire supply chain. There are several notable examples of fully integrated IP supply chains in the oil palm industry, but these are very much the exception as they are more expensive to set up and maintain. Much more commonly, palm oils are traded as global commodities with batches from different sources often being mixed at multiple stages during processing, shipment, refining, storage and eventual delivery to end users.

In the palm oil supply chain, traceability is also intrinsically linked to sustainability. If a product can be traced back to its plantation or mill of origin, it is then possible to investigate whether the plantation or mill of origin is adhering to sustainability regulations, legislation, principles and other relevant criteria. However, monitoring traceability within the palm oil supply chain is a complex, multi-faceted issue. LyonsWhite and Knight (2018) described the supply chain as "being hourglass-shaped, with many different stakeholders at the supply and demand end and a small number of trading companies in the middle. At the production end of the supply chain, it was said that FFBs (fresh fruit bunches) were often traded between multiple smallholders and local traders before arriving at the mill, making the ability to trace the origin of third-party FFBs difficult or impossible". Further downstream, it was reported that the rapid speed and large scale of palm oil trading on commodity markets hindered tracking of consignments, obstructing traceability to mills.

These factors highlight some of the significant challenges faced by the EU as it seeks to ensure that palm oil imports are really from "certified sustainable" sources. For example, can the EU realistically rely on current traceability measures, which even many industry members say are weak and unreliable at present? Or will they look to other methods, such as some of the new and emerging state-of-the-art analytical techniques for traceability purposes? In this case, it is instructive to consider some of the methods that are already used in olive oil and other vegetable oil supply chains as well as newly emerging analytical technologies as will be discussed in the following sections.

\section{Analytical methods for palm oil traceability}

To overcome the challenges presented by current traceability methods (based largely on paper trails, audits, etc.), researchers have been testing and continue to test various analytical techniques for determining the geographical origin of palm oil. The aim is that these methods should supply scientifically accurate data that can accompany current administrative controls, thereby greatly improve traceability in supply chains. Such techniques are usually assessed against several important criteria including analytical speed, cost, instrument sensitivity and selectivity, sample pre-treatment requirements and accessibility for implementation in the field. Perhaps the most important factor to consider is accessibility, in terms of cost and ability for on-site implementation. Whilst a technique could show great technical potential for application, if is too costly then it will not be accessible to laboratories around the world, thus not be adopted as an official method. Likewise, if it is unable to be implemented on-site with ease and without special requirements (vacuum, clean room, etc.) it is again unlikely that it could be adopted as an official analytical traceability technique for global implementation. 
Geographical authentication of vegetable oils has been and continues to be a highly active and productive research area. Essentially, such authentication requires a given sample to carry characteristic chemical fingerprints that reflect its place of origin. In the case of a vegetable oil, this can be best achieved via the assessment of major compounds such as fatty acids (FAs) and triacylglycerols (TAGs), minor components such as carotenes, tocopherols, tocotrienols and sterols, stable isotopes and volatile organic compounds (VOCs). Here, we will briefly discuss the main techniques that have been assessed for determining the geographical origin of palm oil, with the view of facilitating supply chain traceability.

\subsection{Fatty acid analysis}

All acyl lipids contain FA residues, which are classified mainly according to their chain length and the presence or absence of double bonds. FAs are carboxylic acids consisting of a variable length hydrocarbon chain and a terminal carboxyl group. In vegetable oils, the hydrocarbon chain either contains double bonds (unsaturated) or does not contain double bonds (saturated). Whilst detailed literature regarding the extent of compositional variation in palm oils of different provenance is lacking, some studies have indicated that FA composition might vary, albeit according to a limited but measurable extent, based on the geographical origin of the oil (Tres et al., 2011).

The first published study regarding analytical determination of geographical origin of palm oil, utilised gas chromatography (GC) coupled with a flame ionisation detector (FID) for analysis of FA methyl esters (FAMEs) in crude palm oils from three different regions (South East Asia, South America and Africa) (Tres et al., 2013). A statistical method called principal components analysis (PCA) was applied to the palm oil FA data with the PCA revealing some natural clustering which was more or less in agreement with the continent of origin. South East Asian samples formed a tighter cluster than those of African and South American samples. Another statistical method, partial least square-discriminant analysis (PLS-DA), was also utilised. Through comparison of PLS-DA score plots with the PLS-DA loading plots, the FAs responsible for the separation of each class were revealed. The authors discovered that South American palm oil was richer in monounsaturated FAs like oleic acid (C18:3 n-3) and eicosenoic acid (C20:1 n-9). Saturated FAs including lauric (C12:0), myristic (C14:0) and palmitic (C16:0) acids were higher in South East Asian palm oil. African palm oil had a higher content of alpha-linolenic acid (C18:3 n-3). The study concluded that the verification of geographical origin, at least on a continental scale, is feasible by means of FA fingerprinting combined with chemometric methods (Tres et al., 2013).

\subsection{Volatile compound fingerprinting}

VOCs are compounds with relatively low boiling points, resulting in high vapour pressures under ambient conditions. This means that VOCs readily evaporate into the surrounding environment, making them useful for headspace analysis. VOC profiles of vegetable oils vary according to geographical origin, climatic conditions, growing conditions, variety, species, etc. This means that, in principle, the VOC profile of a given food sample could be used to generate a unique fingerprint that could shed light on its provenance. Unfortunately, however, VOCs are also affected by many other environmental factors, for example, there is often seasonal variation in VOC composition of vegetable oils, and they can be affected by storage and transportation conditions. These complications can render VOC analysis a challenging factor for traceability if it is used on its own. Nevertheless, VOC analysis can be a useful screening method and, in many cases, certain types of oils have strong and specific VOC signals based on their geographical origin that are not masked by other variables such as storage conditions, seasonal variations, etc.

VOCs can be readily analysed by chromatographic and spectroscopic techniques, perhaps the most prominent being the so-called electronic or e-nose. Ruiz-Samblás et al. (2013) utilised proton transfer reaction-mass spectrometry (PTRMS) for analysis of VOCs present in palm oils from three continents (South East Asia, South America and Africa). PTR-MS is a rapid, non-destructive, one-dimensional technique used for VOC analysis. The headspace of a sample is continuously introduced into a drift tube where it become ionised, and ions are then detected as ion counts by a secondary electron multiplier. PCA and PLS-DA were conducted to develop classification models to verify the geographical origin of palm oil at a continental scale. With PCA, the samples tended to cluster by their continent of origin, a PLS-DA two-level hierarchical approach was then utilised to develop a classification model. The PLS-DA models had some success, with 88, 100 and 100\% accuracy for the South East Asian, African and South American class, respectively.

In our laboratories, we have been exploring the use of a different method, namely GC-Ion mobility spectrometry (IMS), to compare the VOC profiles of palm oils of different geographical origins, with the view of accompanying current administrative controls within palm oil supply chains. GC-IMS is a relatively new technology which relies upon the separation of charged particles under an applied electric field, with separation resulting from differences in their cross-sectional collision surface areas and shapes. IMS can be coupled to other techniques such as GC and LC to increase sensitivity and selectivity, and while it has been applied to the analysis of olive oils (Garrido-Delgado et al., 2011) to date it has not been investigated for palm oil analysis. Our preliminary results as shown in Figure 4, demonstrate the potential utility of this method for rapid and cost-effective analysis of the VOC profiles of palm oils from different geographical regions, ranging from Malaysia and Africa to South America. For example, in the data presented in Figure 4, the VOCs labelled $22,23,24$ and 25 are only present in Colombian crude palm oil, therefore might be characteristic of palm oils produced in Colombia, thus potentially useful as a rapidly accessible chemical fingerprint. The main benefits of GC-IMS are its low cost, rapid sample throughput and small instrumental footprint meaning that it could be suitable for use in preliminary screening of oils in the field, as well as in larger analytical laboratories. We are now conducting further studies to assess potential of this technology for deployment in palm oil supply chains. 


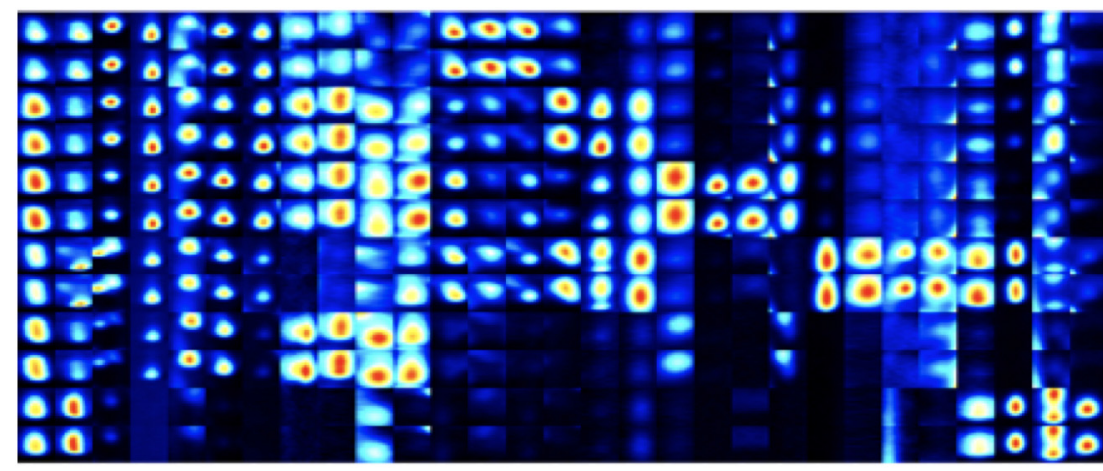

Nigerian Crude Palm Oil

Ecuadorian Crude Palm Oil

Mixed Origin Crude Palm Oil

Colombian Crude Palm Oil

Malaysian Crude Palm Oil

Ghanaian Crude Palm Oil

Fig. 4. A gallery plot generated from GC-IMS analysis showing 29 selected VOC samples. Each column shows a separate VOC, whilst each row represents a sample. This viewer is useful for visualising similarities and differences in VOC composition of different samples. VOC analysis of crude palm oil (CPO) was performed using a FlavourSpec ${ }^{\odot}$ (G.A.S GmbH, Dortmund, Germany) using an autosampler with an integrated agitator and heating block for automated sample handling. $10 \mathrm{~mL}$ of each CPO sample was provided in a $20 \mathrm{~mL}$ glass vial. Prior to analysis, each sample was melted in an agitated water bath for $15 \mathrm{~min}$ at $45^{\circ} \mathrm{C}$ and $275 \mathrm{rpm}$, to allow an aliquot of $1 \mathrm{~g}$ of CPO sample to be taken and placed into a $20 \mathrm{~mL}$ glass headspace vial. Each vial was closed with a polytetrafluorethylene-sealed magnetic screw cap. Following sample conditioning by the autosampler, $200 \mu \mathrm{L}$ of headspace was automatically injected into the system for analysis.

\subsection{Triacylglycerol fingerprinting}

Given that biosynthetic pathways of lipids tend to be species-specific, the evaluation of TAG FA profiles can be useful for authenticating vegetable oils at least according to the crop of origin. Within an individual crop oil, it may be possible to distinguish between cultivars or regions based on more detailed positional analysis of the FAs. Such analysis can be problematic, however, due to the high number of possible FA combinations on the glycerol backbone. TAG analysis can be performed using several chromatographic techniques including thin-layer chromatography (TLC), reversed phase-high performance liquid chromatography (RP-HPLC) and high temperature gas chromatography (HTGC).

Ruiz-Samblás et al. (2013) developed two new methods and authentication models based on HPLC coupled to a charged aerosol detector (CAD) and HTGC-mass spectrometry (MS), for fingerprinting of TAGs from crude palm oils. They compared profiles of palm oils from three different continents, namely South East Asia, Africa and South America. PLS-DA was applied to the data to discriminate the origin of the oils. The rates of successful prediction of geographical origin, based on TAGs, varied between 70 and $100 \%$.

\subsection{Phytosterols}

Phytosterols are a plant-specific subgroup of the steroid group of naturally occurring organic molecules. Phytosterols have been used as tools to evaluate oil authenticity because different crop species have different characteristic compositional profiles, this means they could also be useful for distinguishing by geographical origin. Vegetable oil-derived phytosterols are most commonly analysed using chromatographic techniques as these provide the most information about sterol composition, however, most methods usually require some form of sample pre-treatment.
Pérez-Castaño et al. (2015) used two different normalphase (NP) HPLC (HPLC-UV and HPLC-CAD) systems to discern the geographical origin of palm oil from South East Asia, South America and West Africa, via their sterolic fingerprints. Prior to chromatographic analysis, a methylation reaction was applied on all palm oil samples. Samples were then analysed with a 20-minute run time. Following chromatographic analysis, several additional methods were utilised. Firstly, a pre-processing method named "MEDINA" which improves the quality of the raw data and improves alignment. Exploratory analysis and classification were conducted via PCA, PLS-DA and soft independent modelling by class analogy (SIMCA). Finally, external validation of classifiers was conducted. PCA plots allowed the authors to distinguish two groups separated on the first principal component which were correlated with American and Asian samples. Sterolic profiles of the African samples had no specific pattern and were similar to samples from the other classes. The authors state that this could be explained by the common African origin of all commercial palm oils as they are all ultimately derived from the African oil palm that was only transplanted to other parts of the world during the past two centuries. The authors concluded that in strictly technical terms, none of the tested classifiers showed enough assurance to enable them to be applied in practice to discern the geographical origin of any sample of palm oil, since in the best case, $15 \%$ of samples would be erroneously classified.

\subsection{Transesterified fraction analysis}

Obisesan et al. (2017) followed the same protocol as above, for analysis of the transesterified fraction, but utilised chromatographic data fusion for the authentication of geographical origin. High- and mid-level data fusion strategies were applied. High-level data fusion combines the classification results obtained from each instrumental technique, in this case, the probability of assignation to one class given by 
HPLC-UV to HPLC-CAD models. Mid-level data fusion combines variables selected from each instrumental technique and concatenates them into a single vector. The authors state that all three data-fusion strategies utilised were better at authenticating the geographical origin of palm oil than the individual models, which shows that the information obtained from both chromatograms has a synergistic effect. The authors concluded that although high-level data fusion has the extra advantage that it can be applied to all types of measurement, it should be kept in mind that measuring by more than one technique can increase overall costs and the time of the analytical procedure.

\subsection{Stable isotope ratios}

Isotopes are atoms of an element with the usual number of protons and electrons, but different numbers of neutrons. Whilst they have the same atomic number as the regular element, their mass numbers differ. There are two kinds of isotopes: stable and unstable, with unstable isotopes more commonly being known as radioactive isotopes. There are approximately 300 known naturally occurring stable isotopes, the most commonly utilised in vegetable oil provenance research are $\delta^{13} \mathrm{C}, \delta^{2} \mathrm{H}$ and $\delta^{18} \mathrm{O}$. These isotopes are useful for verifying geographical provenance because their ratios in a given crop can vary according to a range of conditions including climate, fertilisation regime and soil type. Hydrogen and oxygen isotope ratios reveal the water-associated processes in plants that provide information regarding water source acquisition, whilst carbon isotope ratios reflect the environmental effects on photosynthesis.

A recent study by Muhammad et al. (2017) looked at variation of the three aforementioned stable isotopes in crude palm oil from different regions within Malaysia, to assess them as a key traceability parameter. In this study, a Flash 2000 Elemental Analyzer (EA) coupled to a Delta V Advantage isotope ration mass spectrometer was used for the analysis of $\delta^{13} \mathrm{C}$, whilst a Thermo Finnigan Temperature Conversion/EA coupled to a Delta $\mathrm{V}$ isotope ratio mass spectrometer was used for analysis of $\delta^{2} \mathrm{H}$ and $\delta^{18} \mathrm{O}$. The isotopic ratios of $\delta^{2} \mathrm{H}$ and $\delta^{18} \mathrm{O}$ were high, coinciding with the low elevation, coastal location and warm climate where oil palms are usually grown. Hence, no significant difference $(P>0.05)$ was found between palm oil of Northern and Southern regions in Peninsular Malaysia. The $\delta^{2} \mathrm{H}$ and $\delta^{18} \mathrm{O}$ values of East Malaysia were relatively depleted in their heavy isotopes, indicating high elevation and inland geographical origin - a true finding given the majority of plantations in Sabah were initially standing forests in the highlands. $\delta^{13} \mathrm{C}$ values were significantly different $(P<0.05)$ from one another. The variations between regions due to climate and geology could provide unique geographical fingerprints for respective regions, which would be useful for traceability purposes. Similar data have been reported in a study of olive oils by Portarena et al. (2014), which indicates that this might be a generally applicable method, provided the lab had access to this often costly instrumentation.

Three statistical methods were also applied to stable isotope analysis of palm oils from Malaysia as follows: hierarchical cluster analysis, PCA and orthogonal PLS-DA. (i) Hierarchical cluster analysis is an unsupervised method used to distinguish and classify objects into clusters based on their similarities according to the relative contribution of variables. HCA was applied to a dataset containing 33 samples from five different regions in Malaysia. All samples were correctly assigned to their respective state using this method. (ii) PCA was used to detect outliers as well as to predict the possible pattern and trend of clustering. No outliers were detected, according to Hotelling's T2 ellipse at 95\% confidence intervals, and samples were classified into clusters by only two principal components (PC). Samples from central, east coast and east Malaysia were potentially differentiated based on regions, however samples from Northern and Southern regions were indistinguishable as they were observed to fall closely to each other and didn't form distinct clusters. (iii) Orthogonal partial least squares discriminant analysis was employed to construct a classification model to demarcate samples based on region with a predicative power of $52.60 \%$. $\delta^{18} \mathrm{O}$ was proposed as the promising discriminatory marker for discerning palm oil samples obtained from different regions.

\subsection{Recommendations and future work relating to palm oil analysis}

Whilst all of the aforementioned methods and techniques are useful examples of how state-of-the-art techniques can be employed for geographical authentication of palm oil, they all have potential flaws that should be addressed in future studies:

- a large sample size is essential for the application of chemometric analyses. For results to be statistically significant and allow for valid and reliable conclusions to be drawn, in general, a minimum class size of 40 should be used for any chemometric approach which seeks to classify data;

- future studies should consider the effects of differences in growing practices on plantations as well as milling and refining processes, which can vary hugely across the sector. If a mill processes fruits from 20 differently managed plantations that may also be growing different palm varieties, then the resultant bulk oil will be a mixture of oil from each of those different plantations, which could potentially introduce huge day-to-day, week-to-week and longer-term variations in oil composition according to which plantations are being sampled at a particular time. It is therefore very important for researchers to gather as much information about their samples as possible, in order to make accurate sense of their results and to improve geographical specificity;

- seasonal variation is another potentially important factor to consider. Oil palm grows continually during wet and dry seasons, but the characteristics of the oil may vary according to such relatively seasons, or according to less predictable episodes such as drought or a haze-induced decline in fruit productivity. Therefore, studies should also be conducted over a number of years to determine the extent to which oil composition is also affected by such longer term environmental factors, as this could significantly determine whether or not a given method is suitable 


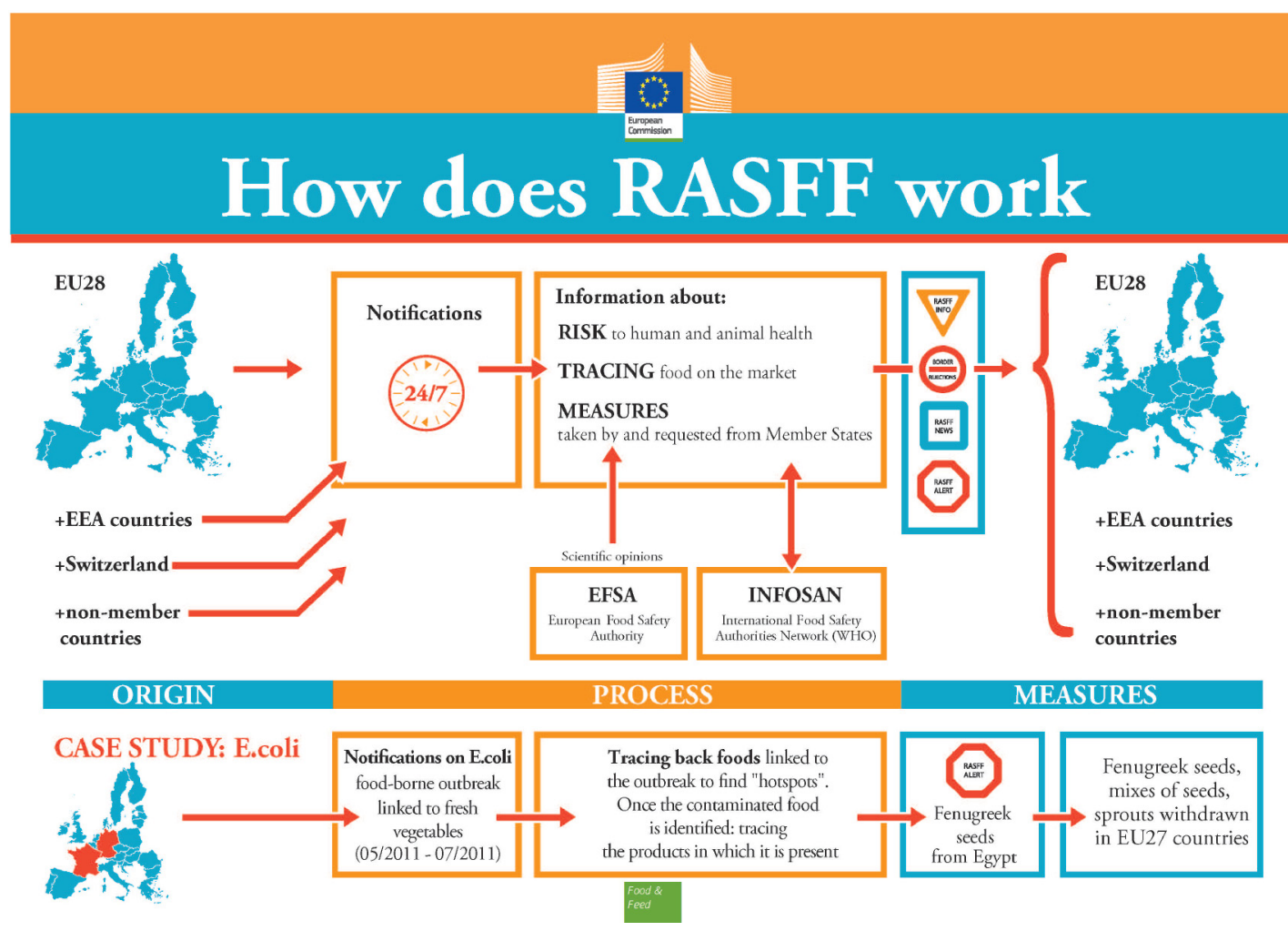

Fig. 5. An overview of the rapid alert system for food and feed (RASFF) notification process (source: https://ec.europa.eu/food/safety/rasff/ how_does_rasff_work_en).

to be used more widely in the industry for traceability purposes;

- evaluation of the robustness of the proposed analytical techniques and methods should be conducted using homogenous planting material (same commercial variety/ progeny/clone) which have been planted under different cultivation regimes and climatic conditions.

\section{Ensuring the safety and authenticity of palm oil entering Europe}

Ensuring the safety and authenticity of foodstuffs is vital for maintaining consumer confidence in food products and for protecting health. If a foodstuff is authentic then it should contain exactly what is described on the label. There is no EU harmonised definition of transgressions in the labelling or expected compositions of foodstuffs, but these practices are usually associated with the term "food fraud" in supply chains. Food fraud covers cases where there is a violation of EU food law, which is usually committed deliberately to realise increased profits through a deliberate process of consumer deception. Committing food fraud can be tempting throughout supply chains due to possibility of increasing profit margins with little risk of adverse consequences to the transgressors, because food fraud has historically been a relatively low priority issue for most police/judicial authorities.

\subsection{The rapid alert system for food and feed (RASFF) process}

If an exporter is trying to access the European market, it is under his responsibility to ensure their products comply with all relevant EU legislation. Those who wish to form strong business relationships often opt to have their products analysed by a trustworthy and well-recognised independent laboratory. This acts as a way to verify the safety and authenticity of their products and enhances their reliability as a reputable business. Regardless of whether such analyses have been conducted, there is a tool called the rapid alert system for food and feed (RASFF) in place for ensuring that food is safe for consumers. The RASFF, created in 1979, enables information to be easily shared between its members (EU-28 National Food Safety Authorities, European Commission, European Food Standards Agency (EFSA), Switzerland, Norway and Iceland). It works to prevent food safety risks before they become detrimental to consumers. It provides $24 / 7$ services to ensure that urgent notifications are sent, received and responded efficiently. RASFF members have designated contact points which are responsible for sending RASFF notifications to the European Commission. The process in which this occurs is described below and displayed graphically in Figure 5:

- food or feed inspectors may inspect a product on the market or at an international border and may take samples to be analysed by an official laboratory;

- if a product is found to be non-compliant then it must be reported within the national system; 
Table 1. Acceptable quality characteristic values as defined by the CODEX-STAN 210-1999 Regulations for named vegetable oils.

\begin{tabular}{ll}
\hline & Maximum level \\
\hline 1.2 Matter volatile at $105^{\circ} \mathrm{C}$ & $0.2 \% \mathrm{~m} / \mathrm{m}$ \\
1.3 Insoluble impurities & $0.05 \% \mathrm{~m} / \mathrm{m}$ \\
1.4 Soap content & $0.005 \% \mathrm{~m} / \mathrm{m}$ \\
1.5 Iron (Fe) & $1.5 \mathrm{mg} / \mathrm{kg}$ \\
Refined oils & $5.0 \mathrm{mg} / \mathrm{kg}$ \\
Virgin oils & \\
1.6 Copper $(\mathrm{Cu})$ & $0.1 \mathrm{mg} / \mathrm{kg}$ \\
Refined oils & $0.4 \mathrm{mg} / \mathrm{kg}$ \\
Virgin oils & \\
1.7 Acid value & $0.6 \mathrm{mg} \mathrm{KOH} / \mathrm{g}$ oil \\
Refined oils & $4.0 \mathrm{mg} \mathrm{KOH} / \mathrm{g}$ oil \\
Cold pressed and virgin oils & $10.0 \mathrm{mg} \mathrm{KOH} / \mathrm{oil}$ \\
Virgin palm oils & \\
1.8 Peroxide values & Up to $10 \mathrm{milliequivalents}$ \\
Refined oils & of active oxygen $/ \mathrm{kg}$ oil \\
& Up to $15 \mathrm{milliequivalents}$ \\
Cold pressed and virgin oils & of active oxygen $/ \mathrm{kg}$ oil \\
\hline
\end{tabular}

Source: http://www.fao.org/docrep/004/y2774e/y2774e04. htm\#bm4.1 (Accessed: 01/08/2018).

- the authority decides whether the issue is of concern to the RASFF and then reports it to the national RASFF contact point;

- the national contact point verifies and completes the notification and forwards it to the European Commission. It uses a comprehensive RASFF notification form to provide details of the findings and measures taken, and adds further relevant documents (bills, analytical reports, etc.) (European Commission, 2017).

The European Commission is obliged to inform a nonmember of RASFF if a product subject to a notification has been exported to that country, or when a product originating from that country has been the subject of a notification, as this allows the country to take corrective measures where required (European Commission, 2017).

\subsection{The issue of food additives}

Perhaps the most common violation of food safety and authenticity is the inclusion of unauthorised additives. Food additives are considered to be any substance not normally consumed as a food in itself, nor is it usually used as a food ingredient. Examples of additives include colouring agents, stabilisers such as antioxidants, preservatives, emulsifiers, sweeteners, and thickeners. A food additive may be included in the European Union's list of allowed additives if:

- it does not pose a risk to consumer health at the proposed level of use (based on available scientific evidence);

- there is a reasonable technological need that cannot be met by other economically and technologically practicable means (European Parliament, 2008);

- its use does not mislead the consumer.
All additives in the EU must be authorised and listed in the EU's "positive" list based on the conditions specified in the Regulation. The Regulation prohibits any food additive or food in which such an additive is present, on the market, if it does not comply with the requirements set out in the Regulation. As we will see in the next Section, the recent detection of unauthorised toxic Sudan dyes illegally added to mimic natural carotenoids and enhance the colour of red palm oil has become an increasingly worrying issue for some retailer outlets in Europe.

\section{Analytical methods for determining palm oil authenticity}

Traditionally, classical physiochemical tests are used within the palm oil industry to determine characteristics such as iodine value (IV), the saponification value or the slip point. It is also important to determine acid value (AV), matter volatile at $105^{\circ} \mathrm{C}$, insoluble impurities, soap content, iron, copper, arsenic, lead and FA composition. Generally accepted values, as indicated by Codex Standard for Named Vegetable Oils (CODEX-STAN 210-1999) including palm oils, are displayed in Table 1 (FAO, 1999).

However, as previously discussed, in order to ensure the safety and authenticity of a product, it is also of great importance to determine the levels of foreign matter. There have been several reported instances of safety and authenticity violations with regards to imported palm oil. A recent example occurred in January 2018, when the Swiss Food Safety and Veterinary Office (FSVO) issued a serious and urgent warning to consumers which advised them to avoid red palm oil produced by companies supplying the branded products labelled as ZOMI or POLIFUDS. The reason for this action was that the Swiss analytical agency had determined that this red palm oil contained the illegal additive Sudan IV, which is banned for use in food as it is a known toxin and is highly carcinogenic (The Federal Council, 2018). Unfortunately, however, this problem is not new. In 2004 and 2005, the authorities in Ghana received 57 and 35 notifications respectively, from the EU RASFF concerning proven cases of the adulteration of Ghana-derived palm oil with Sudan IV (RASFF Portal, 2018).

Whilst there are existing methods in place to detect the illegal addition of additives such as Sudan IV, these traditional methods are often time consuming, costly and require highlytrained personnel. In this section, therefore, we will review some of the newer, state-of-the-art techniques that have been developed to enable more rapid and cheaper detection of various adulterants in edible palm oils. We also examine future prospects for the widespread implementation of such methods within global supply chains.

\subsection{Sudan adulteration in palm oils}

It should be noted that the inclusion of Sudan IV in any foodstuff is completely prohibited by European law, meaning that the threshold for its presence in any edible product is zero. Despite this and the serious health risks associated with this toxic chemical, there are only a few published methods for 
detecting Sudan dyes I-IV in palm oils. For example, it is reported that the relatively old and imprecise method of qualitative thin layer chromatography (TLC) is still used by the UK Food Standards Agency to detect Sudan dyes in food products (Oco and Egroodt, 2006; Genualdi et al., 2016). A similar but more advanced method involving diode array detection (DAD), conversion of the oil to FA methyl esters and further purification by silica gel chromatography has also been used successfully (Uematsu et al., 2007). However, both methods have limitations, namely the inability to simultaneously detect Sudan I-IV and the inability to quantify the presence of Sudan dyes. Thus, there is still a pressing need to develop rapid methods for the simultaneous detection of multiple Sudan dyes and quantification of their presence in foodstuffs.

A recent study by Genualdi et al. (2016) assessed the use of LC-diode array detection (DAD) analysis and LS-MS/MS, for the extraction and detection of Sudan dyes I-IV in palm oil and chilli spices. The study examined both methods for their strengths and weaknesses in identifying adulterated samples. Samples know to be free from Sudan I-IV were deliberately spiked at concentrations close to the limit of detection, in order to validate the methods. A total of 20 brands of red palm oil samples were then analysed for Sudan I-IV using LC-MS/ MS and LC-DAD. Of the 20 brands analysed, four had detectable levels of Sudan I-IV. Concentrations detected by LC-MS/MS ranged from $150-24000 \mathrm{ng} \mathrm{mL}^{-1}$, whilst those by LC-DAD ranged from $240-25000 \mathrm{ng} \mathrm{mL}^{-1}$. These methods overcome the limitations presented by previous methods, they require basic sample preparation and achieve low limits of detection, as well as structural confirmation by MS/MS.

\subsection{Animal fats in palm oils}

In line with the growth of vegetarian diets in many parts of the world, there is a continuing trend for consumers to purchase products prepared from vegetable oils rather than those prepared with animal fats. Another factor affecting consumer choices of fat products is the higher incidence of saturated fats in most animal derived products compared to most plant derived oils. Rightly or wrongly, saturated fats have been associated by much of the general public with increase health risks such as cardiovascular disease. Also, some widely practiced religions, including Islam and Orthodox Judaism, involve the prohibition of consumption of pork and porkderived products, which includes widely used commercial fats such as lard. For these reasons, there is great concern regarding the addition of animal fats, and in particular lard, to palm oils. Lard is commonly used in the manufacture of certain types of pastries, especially in pies, but it has also been illegally added to palm oils. Because lard is a relatively cheap solid fat with a melting point close to that of refined palm oil, it has been used as an adulterant that is difficult to detect except by chemical methods. In terms of food safety, there are no particular issues with lard-adulterated palm oil as they are both relatively highly saturated fats with broadly comparable FA compositions. However, if a consumer who unwittingly purchases adulterated palm oil is a vegetarian or from certain religious groups, then the presence of lard in the palm oil can be regarded as a serious violation of their rights.

Several studies have sought to develop efficient methods for the identification of lard in palm oil, that can be used for the routine screening of oil samples to protect the rights of consumers and to reassure them that the products are free from this highly undesirable adulterant. One of the first, by Marikkar et al. (2002), compared the use of RP-HPLC for TAG analysis, GLC for FAME analysis and differential scanning calorimetry (DSC). Pure, refined, bleached, deodorised (RBD) palm oil samples were adulterated separately with genuine lard (GLD) and enzymatically-randomised lard (ERLD) and analysed using the three methods. Neither GLC nor RP-HPLC were successful in distinguishing adulterated palm oil from pure palm oil. DSC, however, provided a much better means for detection of lard, achieving a detection limit of $1 \%$. In addition to this, DSC did not require any sample pre-treatment and allowed for rapid analysis.

A later study assessed the use of an electronic nose for detecting lard in RBD palm olein. Electronic noses measure the VOCs present in the headspace of a sample. RBD palm olein and lard were mixed in proportions ranging from $1-10 \%$ animal fat, in $1 \%$ increments $(\mathrm{w} / \mathrm{w})$ and from $10-20 \%$, in $5 \%$ increments $(\mathrm{w} / \mathrm{w})$ totalling twelve blends. Lard and RBD palm olein were then analysed separately using the electronic nose and their resulting chromatograms were characteristically different. RBD palm olein contained fewer volatiles that lard, peak areas associated with lard increased significantly $(P<0.05)$ with the increase of lard in blends. There was a significant difference between detector counts for 0 and $1 \%$ lard, showing the possibility of a detection limit of $1 \%$ (Man et al., 2005).

\subsection{3-MCPD in palm oils}

Glycerol-based process contaminants, such as 3-monochloropropanediol (3-MCPD), are found in many vegetable oils, margarines and some processed foods. They are, however, most prevalent in palm oils and raise potential health concerns for consumers. As a result, the European Food Safety Authority (ESFA) have set a tolerable daily intake (TDI) of $0.8 \mu \mathrm{g} \mathrm{kg}^{-1}$ of body weight per day, based on evidence linking its consumption to organ damage in animals (EFSA, 2016).

Detecting their presence by analytical means has become a highly topical area of research. The traditional approaches to determine MCPDs in vegetable fats and oils are based upon chemical derivatization, followed by GC-MS. This approach is widely accepted as a reference method according to AOCS Official Methods. However, these methods cannot give direct information about the identity of MCPDs, they require strong chemicals and complex sample preparation (Crews et al., 2002). Resultantly, researchers are now developing and assessing the use of new state-of-the-art techniques. Recent approaches have included sample purification and enrichment prior to analysis by LC-MS, but due to the high number of analytes, analysis of results soon becomes highly complex (Crews et al., 2002; Dubois et al., 2012). One of the most recent studies assessed the use of GC-IMS in combination with 
LC and time of flight (TOF)-MS, for the analysis of MCPD esters (MCPDEs) in palm oil (Grössl and Nagy, 2017). In this study, the use of GC-IMS enabled quantitative analysis of MCPDEs in their intact form, without any sample preparation (chemical derivatization, enrichment or purification). Furthermore, it allowed for additional selectivity, manifesting primarily in the resolution of interferences (from the components of palm oil), which would usually hinder accurate quantification even at mass resolutions of 100000 full width at half maximum (FWHM) (Grössl and Nagy, 2017).

\section{Conclusions}

The global palm oil industry will continue to expand significantly in the coming decades due to an increasing global population and greater demand for vegetable oils as relatively cheap but calorie-rich food sources. Most of this expansion will take place in Asia, where India and China are already among the greatest importers of palm oils. However, there are indications that demand could also rise in Europe as driven by the need to avoid hydrogenated fats and an increasing avoidance of solid fats derived from animal sources. Europe is also seeking to enforce the importing of only traceable sustainably sourced palm oils into its many downstream market sectors. This means that European palm oil supply chains will need to be monitored and regulated to increasingly rigorous standards. Food safety and authenticity will be a persistent problem and with the increased volume of foodstuffs required to meet demand, there will be an elevated burden placed on food safety laboratories, both public and private. Thus, there is an urgent demand to develop rapid and costeffective analytical methods which allow for high throughput of samples.

Whilst the development of new state-of-the-art techniques is essential for ensuring the safety and authenticity of products, there are still many challenges which must be tackled before such methods can be adopted as officially approved protocols. In particular, many of the methods developed for determining geographical origin of palm oil combine the use of advanced analytical techniques with the application of chemometrics. However, despite the potential of such approaches, the use of small and limited sample sets is likely to limit their application on a wider scale, whilst the upfront and operational costs of each technique can also present major barriers to widespread uptake in the industry. Also, many of the studies reviewed here fail to consider the potential impacts of seasonal variation and differences in growing and processing practices and these need to be factored in for a more realistic assessment of the utility of each method. Looking towards the future, therefore, while there are many exciting new technologies being investigated, there is still much work to be done to improve traceability of palm oils throughout their long and complex supply chains. This work is essential to provide the underpinning quality assurance and control (QA and QC) in palm oil supply chains that is necessary to ensure public safety and maintain consumer confidence in the thousands of food products that contain such oils and their derivatives.

\section{Abbreviations}

3

AV

CAD

DAD

DSC

EA

EFSA

E. guineensis

EU

FAs

FAMEs

FID

FSVO

FWHM

GC

IMS

ISPO

IV

LC

MCPDEs

MS

MSPO

NGO

NP-HPLC

PCA

PDO

PGI

PLS-DA

PTR-MS

RASFF

RBD

RSPO

SIMCA

TAG

TDI

TLC

TOF

TSG

VOCs
MCPD 3-monochloropropane-1,2-diol

Acid value

Charged aerosol detector

Diode array detection

Differential scanning calorimetry

Elemental analyzer

European Food Safety Authority

Elaeis guineensis

European Union

Fatty acids

Fatty acid methyl esters

Flame ionisation detection

Food Safety and Veterinary Office

Full width at half maximum

Gas chromatography

Ion mobility spectrometry

Indonesian Sustainable Palm Oil

Iodine value

Liquid chromatography

Monochloropropanediols esters

Mass spectrometry

Malaysian Sustainable Palm Oil

Non-Government Organisation

Normal phase-high performance liquid chromatography

Principal components analysis

Protected Designation Of Origin

Protected Geographical Indication

Proton transfer reaction-mass spectrometry

Rapid alert system for food and feed

Refined bleached deodorised

Roundtable on Sustainable Palm Oil

Single independent modelling of class analogy

Triacylglycerols

Tolerable daily intake

Thin layer chromatography

Time of flight

Traditional Speciality Guarantee

Volatile organic compounds
Partial least squares-discriminant analysis

\section{References}

510/2006, R. (EC) N. 2006. Council Regulation (EC) No. 510/2006 of 20 March 2006 on the protection of geographical indications and designations of origin for agricultural products and foodstuffs. Off J Eur Union: 0012-0029. Available at: https://eur-lex.europa.eu/ legal-content/EN/TXT/?uri=celex:32006R0510.

CBI Ministry of Foreign Affairs. 2016a. Exporting palm oil to Europe. Available at: https://www.cbi.eu/market-information/ vegetable-oils/palm-oil/ [Accessed: 1 August 2018].

CBI Ministry of Foreign Affairs. 2016b. What requirements should vegetable oils comply with to be allowed on the European market? Available at: https://www.cbi.eu/market-information/ vegetable-oils/buyer-requirements/ [Accessed: 1 August 2018]. 
Crews C, Hough P, Brereton P, et al. 2002. Survey of 3monochloropropane-1,2-diol (3-MCPD) in selected food groups. Food Addit Contam Part A 19: 22-27.

Dubois M, Tarres A, Goldmann T, et al. 2012. Comparison of indirect and direct quantification of esters of monochloropropanediol in vegetable oil. J Chromatogr A 1236: 189-201.

EFSA. 2016. Process contaminants in vegetable oils and foods. Available at: https://www.efsa.europa.eu/en/press/news/ 160503-0 [Accessed: 1 August 2018].

European Commission. 2017. Questions and answers: Rapid Alert System for Food and Feed (RASFF). Available at: http://europa.eu/rapid/ press-release_MEMO-17-2461_en.htm [Accessed: 1 August 2018].

European Parliament. 2008. Regulation (EC) No. 1333/2008 Of the European Parliament and of the Council of 16 December 2008 on food additives. Off $J$ Eu Union. Available at: https://eur-lex. europa.eu/legal-content/EN/TXT/?uri=celex\%3A32008R1333.

European Parliament. 2017. Palm oil and deforestation of rainforests. Available at: http://www.europarl.europa.eu/sides/getDoc.do? pubRef=-//EP//TEXT+TA+P8-TA-2017-0098+0+DOC+XML+V0// EN.

FAO. 1999. Section 2. Codex Standards for fats and oils from vegetable source. Available at: http://www.fao.org/docrep/004/ y2774e/y2774e04.htm\#bm4.1 [Accessed: 1 August 2018].

Garrido-Delgado R, Mercader-Trejo F, Sielemann S, et al. 2011. Direct classification of olive oils by using two types of ion mobility spectrometers. Anal Chim Acta 696(1-2): 108-115. doi: 10.1016/j.aca.2011.03.007.

Genualdi S, MacMahon S, Robbins K, et al. 2016. Method development and survey of Sudan I-IV in palm oil and chilli spices in the Washington, DC, area. Food Addit Contam Part A, Chem, Anal, Control, Expo Risk Assess 33(4): 583-591. Available at: http:// www.ncbi.nlm.nih.gov/pubmed/26824489\%0Ahttp://www.pub medcentral.nih.gov/articlerender.fcgi?artid=PMC4888373.

Grössl M, Nagy K. 2017. Benefits of ion mobility for analyzing monochloropropane-diol esters. Food Addit Contam Part A 0(0). Available at: https://doi.org/10.1080/19440049.2017.1325014.

Indexmundi. 2017. European Union (EU-27) Palm oil domestic consumption by year. Available at: https://www.indexmundi.com/ agriculture/?country=eu\&commodity=palm-oil\&graph=domes tic-consumption [Accessed: 1 August 2018].

Indexmundi. 2018. Palm oil imports by country in $1000 \mathrm{MT}$. Available at: https://www.indexmundi.com/agriculture/?commod ity=palm-oil\&graph=imports [Accessed: 1 August 2018].

Libération. 2015. Mille excuses pour la polémique sur le Nutella. Available at: http://www.liberation.fr/futurs/2015/06/17/mille-excuses-pour-lapolemique-sur-le-nutella_1331883 [Accessed: 1 August 2018].

Lyons-White J, Knight AT. 2018. Palm oil supply chain complexity impedes implementation of corporate no-deforestation commitments. Global Environ Chang. doi:10.1016/j.gloenv cha.2018.04.012.

Man YBC, Syahariza ZA, Mirghani MES, et al. 2005. Detection of lard adulteration in RBD palm olein using an electronic nose. Food Chem 90(4): 829-835. doi: 10.1016/j.foodchem.2004.05.062.

Marikkar JMN, Lai OM, Ghazali HM, et al. 2002. Compositional and thermal analysis of RBD palm oil adulterated with lipasecatalyzed interesterified lard. Food Chem 76(2): 249-258. doi: 10.1016/S0308-8146(01)00257-6.

Meijaard E, Garcia-Ulloa J, Sheil D, et al. 2018. Oil palm and biodiversity. A situation analysis by the IUCN Oil Palm Task Force.
Michail N. 2016. France to vote on palm oil tax. Available at: https:// www.foodnavigator.com/Article/2016/03/14/France-to-vote-onpalm-oil-tax [Accessed: 1 October 2018].

Muhammad SA, Seow E, Omar AKM, et al. 2017. Variation of $\delta^{2} \mathrm{H}, \delta^{18} \mathrm{O}$ $\& \delta^{13} \mathrm{C}$ in crude palm oil from different regions in Malaysia: Potential of stable isotope signatures as a key traceability parameter. Sci Justice 170: 413-418.

Murphy DJ. 2014. The future of oil palm as a major global crop: Opportunities and challenges. J Oil Palm Res 26(March): 1-24.

Murphy DJ. 2015. What is the future for oil palm as a global crop? World Agric 5: 24-34.

Obisesan KA, Jiménez-Carvelo AM, Cuadros-Rodriguez L, et al. 2017. HPLC-UV and HPLC-CAD chromatographic data fusion for the authentication of the geographical origin of palm oil. Talanta 170 (April): 413-418. Available at: https://doi.org/10.1016/j. talanta.2017.04.035.

Oco JOVANL, Egroodt JEANAD. 2006. Development of a fast analytical method for the determination of Sudan dyes in chili- and currycontaining foodstuffs by high-performance liquid chromatographyPhotodiode array detection. J Agric Food Chem 54: 639-644.

Pérez-Castaño E, Ruiz-Samblás C, Medina-Rodríguez S, et al. 2015. Comparison of different analytical classification scenarios: application for the geographical origin of edible palm oil by sterolic (NP) HPLC fingerprinting. Anal Methods 7(10): 41924201. Available at: http://xlink.rsc.org/?DOI=C5AY00168D.

Portarena S, Gavrichkova O, Lauteri M, et al. 2014. Authentication and traceability of Italian extra-virgin olive oils by means of stable isotopes techniques. Food Chem 164: 12-16. Available at: https://doi.org/10.1016/j.foodchem.2014.04.115.

RASFF Portal. 2018. Search Page. Available at: https://webgate.ec. europa.eu/rasff-window/portal/?event=SearchForm\&cleanSearch=1 [Accessed: 1 August 2018].

Ruiz-Samblás C, Arrebola-Pascual C, Tres A, et al. 2013. Authentication of geographical origin of palm oil by chromatographic fingerprinting of triacylglycerols and partial least square-discriminant analysis. Talanta 116: 788-793. Available at: https://doi.org/ 10.1016/j.talanta.2013.07.054.

Statista. 2015. Forecasted vegetable oil consumption in the European Union (28 countries) From 2014 to $2026^{*}$ (in 1000 Tonnes). Available at: https://www.statista.com/statistics/489563/forecastvegetable-oil-consumption-european-union-28-eu/ [Accessed: 1 August 2018].

The Federal Council. 2018. Public warning: illegal dye Sudan red IV in palm oil-further product affected. Available at: https://www. admin.ch/gov/de/start/dokumentation/medienmitteilungen.msgid-69658.html [Accessed: 1 March 2018].

Tres A, van der Veer G, Alewijn M, et al. 2011. Palm oil authentication: Classical and state-of-the-art techniques. In: Penna SA, ed. Oil palm: Cultivation, production and dietary components. New York: Nova Science Publishers, Inc., pp. 1-44. doi: 10.3213/1612-1651-10072.

Tres A, Ruiz-Samblas C, Van Der Veer G, et al. 2013. Geographical provenance of palm oil by fatty acid and volatile compound fingerprinting techniques. Food Chem 137(1-4): 142-150. Available at: https://doi.org/10.1016/j.foodchem.2012.09.094.

Uematsu Y, Ogimoto M, Kabashima J, et al. 2007. Fast cleanup method for the analysis of Sudan I-IV and para red in various foods and paprika color (oleoresin) by high-performance liquid chromatography/diode array detection: focus on removal of fat and oil as fatty acid methyl esters prepared by transes. JAOCS, J Am Oil Chem Soc 90(2): 437-445. 